\title{
Macroeconomia do Turismo Argentino em Santa Catarina
}

\section{Macroeconomics of Argentinians Tourism in Santa Catarina}

\author{
Roberto Meurer ${ }^{1}$ \\ Hoyêdo Nunes Lins ${ }^{2}$
}

\begin{abstract}
Resumo
O Estado de Santa Catarina experimentou um considerável crescimento do setor de turismo nas últimas décadas. O fluxo turístico de origem argentina revelou-se um ingrediente importante dessa trajetória. Este artigo focaliza um aspecto pouco explorado, aparentemente, da participação argentina no turismo estadual: a relação entre a situação macroeconômica do país vizinho e a demanda turística por Santa Catarina lá originada. Começa-se abordando brevemente a problemática geral da macroeconomia do turismo. Depois, discorre-se sobre o crescimento desse setor em Santa Catarina, destacando a presença de argentinos. A terceira parte desenvolve uma análise baseada em tratamento estatístico de dados sobre demanda e receita geradas por esses turistas no estado, com exame das correlações envolvendo taxa de câmbio e taxa de crescimento do PIB da Argentina.
\end{abstract}

Palavras-chave: turismo; Santa Catarina; turistas argentinos; economia argentina

\begin{abstract}
The State of Santa Catarina has witnessed a considerable development of its tourist sector in the last decades. The demand from Argentina has proved to be an important factor of that growth. This article deals with a feature of the presence of Argentinians in the state which seems to be scarcely studied: the relationship between the macroeconomic situation of Argentina and the tourist demand in Santa Catarina originated from that country. The first part of the article considers briefly the general issue of tourism macroeconomics. The second one looks upon tourism growth in Santa Catarina, stressing the presence of visitors from Argentine. The third section develops an analysis based on statistical treatment of data concerning demand and income generated by such tourists in Santa Catarina, involving correlations that consider aspects like exchange rate and the rate of GDP increase in Argentina.

Keywords: tourism; Santa Catarina; tourists from Argentina; Argentina's economy
\end{abstract}

\footnotetext{
${ }^{1}$ Economista e Doutor em Engenharia de Produção. Professor do Departamento de Ciências Econômicas e do Programa de Pós-Graduação em Economia da Universidade Federal de Santa Catarina. E-mail: rmeurer@mbox1.ufsc.br.

${ }^{2}$ Economista e Doutor em Geografia (Organização do Espaço). Professor do Departamento de Ciências Econômicas e do Programa de Pós-Graduação em Economia da Universidade Federal de Santa Catarina. E-mail: hnlins@cse.ufsc.br.
} 


\section{Introdução}

O Brasil não foi deixado à margem da expansão que o setor de turismo vem apresentando em escala mundial. É sugestivo dessa condição o destaque que a revista The Economist deu ao país pouco tempo atrás, quando estampou que a "indústria turística do Brasil tem crescido rapidamente em anos recentes, e deve continuar a crescer (...)” (THE ECONOMIST, 2000, p. 66). A trajetória percorrida está longe de significar ausência de limitações e problemas no turismo brasileiro, mas parece claro que o "fenômeno turístico" passou a caracterizar amplamente áreas que não pertencem ao rol de destinos tradicionais no país, florescendo muito além de cidades como o Rio de Janeiro e de capitais do Nordeste como Salvador e Fortaleza.

Santa Catarina tem marcado presença no turismo nacional, conforme assinalado, por exemplo, em Lins et al. (2002). É eloqüente a esse respeito que a capital catarinense figure entre as dez cidades brasileiras mais visitadas por estrangeiros em 2002 e 2003, anos para os quais estão disponíveis os dados mais recentes sobre este aspecto, e que o estado tenha canalizado uma fração não negligenciável - 5,6\% e 6,4\%, pela ordem, nesses dois anos - das entradas dos turistas oriundos da Argentina, o mercado emissor que mais participa individualmente do fluxo internacional para o Brasil, contribuindo com pouco menos de 1/5 do total de chegadas no país (EMBRATUR, 2004).

Diferentes estudos têm abordado aspectos específicos da experiência catarinense como destino turístico. Produzidas geralmente em ambiente acadêmico, as análises tentam captar os reflexos e conseqüências do crescimento do setor. Os temas explorados são múltiplos, incluindo impactos socioeconômicos, problemas ligados ao meio-ambiente e questões de ordem cultural e institucional. Podem ser indicados como ilustrações, entre vários outros, o estudo de Lins (1993) sobre uma localidade tradicional da Ilha de Santa Catarina enredada no turismo de massa, a Barra da Lagoa, e a pesquisa de Ouriques (1998) sobre as condições de trabalho no turismo na capital de Santa Catarina.

Muito menos freqüentes são as tentativas de olhar "macroeconomicamente" para o turismo no estado. É fato que as pesquisas sobre a demanda turística realizadas periodicamente pela Santa Catarina Turismo S.A. (SANTUR), órgão estadual dedicado à promoção do setor, procuram detectar o significado econômico da movimentação turística com base em dados sobre os gastos dos visitantes. Mas pouco (se tanto) foi feito para associar o fluxo turístico, e os vinculados 
resultados no tocante a gastos (com hospedagem e alimentação, principalmente), aos processos em curso em nível mais geral, quer dizer, em escala macroeconômica. Isso se inscreve num quadro mais geral, como sugere a lacuna observada na literatura no tocante ao comportamento e à previsão das receitas com viagens internacionais e ao número de turistas no Brasil, uma situação que contrasta com a de outros países, segundo evidencia o artigo resenha de Lim (1997). Uma exceção para o caso brasileiro relaciona-se aos trabalhos de Rabahy (1990; 1992), que apresentam tratamento analítico e quantitativo sobre tais assuntos.

Tendo em vista a magnitude do afluxo argentino em Santa Catarina, indicativo da importância desse mercado emissor para o estado, esse assunto mostra particular relevância quando se considera o movimento de turistas do país vizinho. Cabe indagar, por exemplo, na busca de uma dimensão mais abrangente (ou estrutural) do turismo estadual relacionado à demanda argentina, sobre o quanto a vinda de argentinos para Santa Catarina é comandada pelo desempenho da economia daquele país, traduzido na evolução do seu produto interno bruto (PIB). Ou sobre o quanto o fluxo e o nível de gastos desses turistas guardam relação com a taxa real de câmbio da moeda brasileira vis-à-vis a moeda argentina.

Interrogações desse tipo inscrevem-se no campo de uma, por assim dizer, "macroeconomia do turismo catarinense", tanto mais importante haja vista o freqüente estado de inquietação dos agentes turísticos estaduais com as oscilações do mercado argentino. Por exemplo, às vésperas da alta estação de 2001-2002, o jornal Folha de S. Paulo anunciava em manchete que "SC investe para substituir turista argentino" (FOLHA DE SÃO PAULO, 2001, p. B1). Objetivo: "compensar fuga de argentinos devido à crise" (ibid). Ou seja, quem diz "macroeconomia do turismo" referese não só à reflexão sobre a problemática geral da economia do turismo, como fazem, entre outros, Lage e Milone (1991). Faz também referência, e talvez principalmente, aos limites e possibilidades de promoção do desenvolvimento turístico por meio de políticas.

A "macroeconomia do turismo" assim considerada - com interesse em perscrutar a importância das condições econômicas na Argentina - constitui o objeto do presente artigo. O ponto de partida é uma (muito) breve abordagem sobre a problemática geral da macroeconomia do turismo. Depois discorre-se sobre o crescimento do setor turístico em Santa Catarina, destacando a presença de argentinos. A terceira parte desenvolve uma análise baseada em tratamento 
estatístico de dados sobre demanda e receitas geradas pelos turistas argentinos no estado, com exame das correlações envolvendo taxa de câmbio e taxa de crescimento do PIB do país vizinho.

\section{Turismo e Macroeconomia}

Falar sobre o turismo em termos macroeconômicos significa fazer referência aos reflexos do funcionamento desse setor em termos agregados. Esse ângulo de observação implica considerar o modo como o conjunto das atividades enfeixadas no setor reverberam ao nível de uma economia, por exemplo, nacional, e também examinar o grau dessa reverberação. Nessa perspectiva, privilegia-se o papel de "vetor" de resultados macroeconômicos ostentado pelo turismo, um tipo de desempenho observado junto a quaisquer outras atividades, seja na indústria, na agricultura ou no amplo espectro dos serviços, grupo ao qual pertence o próprio setor em questão.

São considerações de cunho macroeconômico que permitem pôr em relevo, por exemplo, que a velocidade do crescimento das receitas cambiais provenientes do turismo é maior do que a do crescimento das exportações, em termos mundiais (Tabela 1). De fato, a proporção das receitas cambiais turísticas na comparação com as receitas das exportações passou de um patamar em torno de $6 \%$, no começo da década de 80 , para um nível superior a $8 \%$ nos anos 90 , embora tenha havido um recuo no início da década em curso.

Tabela 1: Receita cambial mundial de exportações e turismo: 1982-2002 (US\$ Bilhões)

\begin{tabular}{|c|c|c|c|}
\hline Anos & Exportações (A) & Turismo (B) & B/A * 100 \\
\hline 1982 & $1.880,6$ & 100,9 & 5,60 \\
\hline 1984 & $1.864,2$ & 112,7 & 6,05 \\
\hline 1986 & $2.058,0$ & 143,5 & 6,97 \\
\hline 1988 & $2.779,5$ & 204,3 & 7,35 \\
\hline 1990 & $3.438,6$ & 268,9 & 7,82 \\
\hline 1992 & $3.764,3$ & 315,1 & 8,37 \\
\hline 1994 & $4.286,7$ & 354,0 & 8,26 \\
\hline 1996 & $5.350,9$ & 435,6 & 8,14 \\
\hline 1998 & $5.450,0$ & 442,5 & 7,51 \\
\hline 2000 & $6.362,8$ & 477,9 & 7,57 \\
\hline 2002 & $6.384,5$ & 483,0 & \\
\hline
\end{tabular}

Fonte: EMBRATUR (2004) 
É igualmente uma visão macroeconômica concentrada nos efeitos agregados das atividades turísticas que subjaz à previsão do World Travel \& Tourism Center, segundo a qual o setor de viagens e turismo mundial gerará em 2005, diretamente e indiretamente, 221,6 milhões de empregos e US\$ 4.745,7 bilhões de produto interno bruto (PIB). Esses montantes equivaleriam a $8,3 \%$ do emprego total e a $10,6 \%$ do PIB total (WTTC, 2005a).

No que concerne ao Brasil, é nos termos de uma "macroeconomia do turismo" que se pode referir ao comportamento da Conta Turismo do Balanço de Pagamentos do país. No intervalo 19932003, os ingressos proporcionados pelo turismo - representando a receita cambial ligada ao setor - apresentou tendência ascendente, mesmo que nos três primeiros anos da presente década tenha ocorrido alteração, em movimento todavia pendular. As despesas, de seu lado, cresceram até 1998 e depois se engajaram em trajetória descendente, alcançando em 2003 um patamar não muito superior ao do início do período observado (Tabela 2).

Tabela 2: Conta Turismo do Balanço de Pagamentos do Brasil: 1993-2003 (US\$ Mil)

\begin{tabular}{|c|c|c|c|}
\hline Anos & Receita & Despesa & Saldo \\
\hline 1993 & 1.091 .419 & 1.892 .027 & $(800.608)$ \\
\hline 1994 & 1.924 .800 & 2.930 .900 & $(1.006 .100)$ \\
\hline 1995 & 2.097 .100 & 3.411 .900 & $(1.314 .800)$ \\
\hline 1996 & 2.469 .146 & 4.438 .000 & $(1.968 .854)$ \\
\hline 1997 & 2.594 .884 & 5.446 .000 & $(2.851 .116)$ \\
\hline 1998 & 3.678 .029 & 5.732 .000 & $(2.053 .971)$ \\
\hline 1999 & 3.994 .144 & 3.085 .000 & 909.144 \\
\hline 2000 & 4.227 .606 & 3.893 .000 & 334.606 \\
\hline 2001 & 3.700 .887 & 3.199 .000 & 501.887 \\
\hline 2002 & 3.120 .132 & 2.380 .000 & 740.132 \\
\hline 2003 & 3.385 .967 & 2.261 .000 & 1.124 .967 \\
\hline
\end{tabular}

Fonte: EMBRATUR (2004)

Esse perfil das despesas traduz movimentação de viagens de turistas brasileiros ao exterior que apresenta uma correspondente oscilação. O saldo da conta mostra que até 1998 os gastos de turistas nacionais em outros países superaram os gastos dos turistas estrangeiros no Brasil, e que desde então vigora a situação contrária. É igualmente o nível macro de observação sobre o Brasil que permite ao já aludido World Travel \& Tourism Center prever que, em 2005, o PIB gerado pelos setores de viagens e turismo, adicionado ao vinculado às atividades que interagem com 
estes, representará algo como 7,2\% do PIB brasileiro total. No que toca aos empregos, nas mesmas condições, a percentagem estimada é 7\% (WTTC, 2005b).

A referência às interações em meio às quais opera o setor de turismo permite evocar um importante campo de abordagem macroeconômica sobre as atividades em questão. É o relativo aos efeitos multiplicadores do turismo, objeto de diferentes contribuições objetivando aperfeiçoar os procedimentos que captam os impactos socioeconômicos do setor e, simultaneamente, inspiração de numerosas investigações sobre realidades turísticas nacionais ou regionais. Do que se trata, em termos amplos?

a noção de multiplicador ligado à atividade turística corresponde a um conceito extremamente simples e verificável na realidade. Enfim, parece evidente que o dinheiro deixado pelo turista, pelo pagamento do hotel e da estada, venha a passar por todos os setores da economia de uma nação. Esta primitiva despesa não fica nas mãos do hoteleiro ou do dono do restaurante que a recebe, mas é utilizada para pagamento dos vários bens e serviços necessários a estes últimos para assegurar os serviços requisitados pelo turista. Ao seu redor, uma quantidade de moeda 'inferior', referente à parte do lucro e de remuneração, sobra nas mãos destes primitivos agentes econômicos, que a transferem aos agentes econômicos de outros setores.

Nesta longa série de transferências, também, a moeda originada em seguida da primitiva despesa do turista, vem, num determinado período de tempo, a propagar-se nos vários setores da economia nacional, ativando-a toda no seu complexo e contribuindo para incrementar de maneira mais que proporcional a renda nacional. (SESSA, 1983, p. 55)

Vale assinalar que, embora a idéia de multiplicador turístico tenha sentido lógico, em virtude dos encadeamentos e interações que leva em conta, não se deve pensar que o tema é imune a controvérsias. Como salienta Sessa (op cit.), com efeito, o assunto enseja discussões. Muito do que é debatido tem a ver com a própria percepção dos mecanismos do multiplicador, o que tem efeito sobre a forma de cálculo.

Igualmente importante, e também com reflexos de ordem técnica, é a questão da magnitude do multiplicador conforme os tipos de estruturas socioeconômicas e institucionais em que se desenrolam atividades turísticas. O núcleo do problema vincula-se às "fugas" do efeito multiplicador. Por exemplo, se um país necessita realizar grandes importações para assegurar o funcionamento do seu setor de turismo, parcela considerável da renda gerada (direta e indiretamente, e também de forma induzida) pelos gastos dos turistas se materializará externamente. Em outras palavras, se as interdependências locais são rarefeitas, o efeito 
multiplicador é, em maior ou menor grau, transferido ou "filtrado". Esse tipo de percepção tem figurado nas análises de vários observadores sobre as experiências de promoção do setor de turismo em países do Terceiro Mundo, tanto na América Latina como na África e na Ásia (conforme, por exemplo, MADELEY, 1987, e SALL, 1987).

Disso decorre o entendimento de que promover o desenvolvimento socioeconômico com suporte no turismo requer a diversificação da base econômica da área considerada. Proceder desse modo não só contribui para ampliar a reverberação local dos impulsos emanados do turismo, com expressão no multiplicador, como possibilita reduzir a dependência - ou o aprisionamento - das estruturas locais em relação a um único setor de atividade. Isso parece tanto mais estratégico haja vista que o setor de turismo, pela sua natureza, é pouco suscetível de "controle" no âmbito dos núcleos receptores. Realmente, além de melhorar a atratividade - o que já representa, assinale-se, um leque bastante amplo de iniciativas e providências -, pouca coisa pode ser feita no plano local para garantir a vinda de turistas. A razão é que a demanda turística é condicionada por vários fatores, muitos dos quais se encontram fora de alcance das medidas protagonizadas nos próprios mercados receptivos.

Essa alusão aos ambientes turísticos, como praticamente reféns dos determinantes estruturais da movimentação de turistas, permite chamar a atenção para o caráter "reflexo das condições macroeconômicas" também ostentado pelo turismo. Isso é importante, pois falar em termos macroeconômicos sobre o setor não significa somente referir às conseqüências do funcionamento deste em escala agregada.

Explorar essa direção implica inverter a perspectiva e destacar que a movimentação turística espelha a situação da economia. Por mais que o ócio e o lazer sejam importantes para o ser humano na sociedade industrial, como enfatiza Krippendorf (1989), as viagens turísticas normalmente ocorrem quando as pessoas experimentam disponibilidade de recursos, quer dizer, quando as suas outras necessidades, mais prementes, mostram-se mais ou menos equacionadas. Daí ser lógico intuir uma relação causal em que o turismo aparece como beneficiário das fases de expansão econômica, quando a tendência é o aumento na renda e no emprego.

Para focalizar essa outra perspectiva - a macroeconomia operando como condicionante do turismo - é útil, pelo menos a título de ilustração, voltar à tabela 1, que apresenta a Conta Turismo do Balanço de Pagamentos do Brasil. O crescimento do saldo negativo dessa conta até 
1997 e a mudança para saldo positivo entre 1998 e 1999 são processos que podem ser associados, numa relação de causa e efeito, à política de câmbio que sustentou o Plano Real. A apreciação da moeda brasileira estimulou cidadãos desse país a viajar mais ao exterior, o que refletiu na progressão dos gastos. Com a desvalorização, levada a cabo no início de 1999, o encarecimento das viagens certamente inibiu os deslocamentos, resultando no encolhimento das despesas realizadas por brasileiros no exterior.

Numa palavra, o setor de turismo é a um só tempo tributário e reflexo das condições macroeconômicas. A abordagem que ocupa a quarta parte do artigo privilegia esse segundo ângulo de associação entre turismo e macroeconomia. Como indicado na introdução, estará em análise o vínculo entre as condições macroeconômicas da Argentina e os resultados do turismo catarinense vinculados à presença de argentinos.

\section{Turismo em Santa Catarina: um esboço}

Santa Catarina passou a despontar como destino turístico de relevo na segunda metade dos anos 70, quando visitantes gaúchos, principalmente, mas também argentinos, deixaram clara a sua opção por férias e lazer no litoral do estado. Desde então, e na esteira de um inegável e crescente dinamismo na movimentação turística ao longo dos anos 80 e 90, Santa Catarina inscreveu um novo setor de atividades no seu perfil econômico. A expansão do fluxo turístico estimulou investimentos no aparato receptivo - meios de hospedagem e elementos da estrutura de alimentação e gastronomia, no essencial, mas também na área de lazer e entretenimento -, e esses gastos contribuíram para magnetizar a demanda, numa relação que faz lembrar (claro que de forma estilizada) uma espiral ascendente.

Assinale-se que a origem dos turistas brasileiros que demandam Santa Catarina é basicamente a Região Sul do país. Na alta estação de 2005 (meses de janeiro e fevereiro), por exemplo, 3/4 dos que foram registrados como turistas nacionais pela pesquisa realizada pela SANTUR (SANTUR, $2005)$ provinham do Paraná $(27,4 \%)$, do Rio Grande do Sul $(24,3 \%)$ e do próprio Estado de Santa Catarina $(22,6 \%)$.

Duas considerações básicas devem ser feitas sobre essa evolução turística. Uma é que o turismo catarinense tem na grande franja litorânea do estado o seu espaço por excelência de operação. De fato, o "atributo praia", pertencente ao leque de atrações vinculadas à estrutura paisagístico- 
ambiental, ocupa posição de proa nas motivações dos turistas quanto à escolha de Santa Catarina como destino. Isso significa que o turismo é sazonal - trata-se de um turismo de verão em enorme medida - e desigualmente distribuído no território catarinense.

A sazonalidade pode ser constatada nas informações sobre entradas de turistas apresentadas no mais recente Anuário Estatístico da EMBRATUR em disponibilidade (EMBRATUR, 2004): em 2003, 57,4\% das entradas de turistas em Santa Catarina tiveram lugar nos meses de janeiro e fevereiro; no Brasil como um todo a correspondente proporção não ultrapassa $23,4 \%$. No que diz respeito à incidência geográfica, vale destacar que a influência recíproca entre fluxo de visitantes e investimentos vem galvanizando a anatomia observada: como informa a tabela 3, a grande maioria dos processos de financiamento para empreendimentos turísticos aprovados pela Agência Catarinense de Fomento S.A. (BADESC) nos anos 90 refere-se a municípios litorâneos.

Tabela 3: Processos de financiamento para empreendimentos turísticos aprovados pelo BADESC: dados agregados para o período 1990-2001

\begin{tabular}{|l|c|c|c|c|c|c|}
\hline \multirow{2}{*}{ Localização } & \multicolumn{2}{|c|}{$\mathrm{N}^{\mathrm{o}}$ de processos contratados } & \multicolumn{3}{|c|}{ Valor financiado (US\$ mil) } \\
\cline { 2 - 7 } & Hotéis & Outros & Total & Hotéis & Outros & Total \\
\hline Municípios litorâneos & 70 & 13 & 83 & $16.977,7$ & 494,3 & $17.472,0$ \\
- Florianópolis & 36 & 6 & 42 & $10.807,6$ & 185,5 & $10.993,1$ \\
- Balneário Camboriú & 22 & 3 & 25 & $4.702,4$ & 155,8 & $4.858,2$ \\
\hline Municípios não litorâneos & 38 & 20 & 58 & $6.534,5$ & 750,5 & $7.285,0$ \\
\hline Total & 108 & 33 & 141 & $23.512,2$ & $1.244,8$ & $24.757,0$ \\
\hline
\end{tabular}

Fonte: BADESC (In: LINS et al, 2002)

Obs.: os dados de 2001 referem-se ao período de janeiro a junho

Ressalte-se todavia que o envolvimento do litoral não é homogêneo, como a tabela 3 já sugere. Dados para a alta estação de 2001 permitem constatar que somente dois núcleos receptores litorâneos canalizam a maior parte da movimentação turística, com reflexos em nível de gastos. Trata-se do Município de Florianópolis - essencialmente a Ilha de Santa Catarina - e do Município de Balneário Camboriú, este situado no litoral norte do estado. Naquela alta estação ambos registraram, em conjunto, pouco menos da metade dos turistas e quase $70 \%$ dos gastos turísticos totais (Tabela 4). Esses municípios aparecem com grande destaque também na tabela 3, 
pois abrigaram a esmagadora maioria dos empreendimentos que se beneficiaram de recursos para investimentos aprovados pelo BADESC.

A outra consideração básica sobre a trajetória do turismo catarinense refere-se ao subaproveitamento do potencial turístico existente. Santa Catarina apresenta considerável diversificação de atributos para turismo, como indica o material de divulgação utilizado SANTUR (S/D). À guisa de síntese, cabe pelo menos fazer referência, além dos circuitos litorâneos - redutos, como se frisou, do que ocorre de mais importante em termos turísticos -, aos circuitos histórico-culturais, de festas típicas (entremeados com os anteriores), de inverno, de águas termais e de compras, com incidência em diferentes regiões do estado.

Embora alguns circuitos revelem uma certa vitalidade, por conta, entre outras coisas, de esforços promocionais de prefeituras e do governo estadual, não se pode dizer que atingiram nível de desenvolvimento que represente contrapeso ao domínio avassalador do turismo de verão. Também não alterou esse perfil o conjunto de movimentos recentes no turismo estadual, englobando o avanço do turismo religioso em Nova Trento, puxado pela canonização da Santa Paulina (FARAH, 2002), o enraizamento da prática de observação de baleias franca na área de Imbituba, entre agosto e novembro (PLIGER, 2002), e a expansão do turismo de eventos (PAVEI, 2001; VANIN, 2001).

Tabela 4: Participação dos principais municípios turísticos do litoral catarinense na movimentação turística de janeiro e fevereiro de 2001

\begin{tabular}{|l|c|c|c|c|}
\hline \multirow{2}{*}{ Destino turístico } & \multicolumn{2}{|c|}{ Total de turistas (mil) } & \multicolumn{2}{c|}{$\begin{array}{c}\text { Gasto turístico total } \\
\text { (US\$ milhões) }\end{array}$} \\
\cline { 2 - 5 } & Quantidade & $\%$ & Quantidade & $\%$ \\
\hline Santa Catarina & $2.763,2$ & 100 & 477,49 & 100 \\
\hline $\begin{array}{l}\text { Litoral Central } \\
\text { - Florianópolis }\end{array}$ & 552,9 & 20,0 & 163,15 & 34,2 \\
\hline Litoral Norte & & & & \\
- Balneário Camboriú & 767,6 & 27,8 & 170,50 & 35,7 \\
- Bombinhas & 131,5 & 4,8 & 33,65 & 7,0 \\
- Itapema & 187,8 & 6,8 & 42,44 & 8,9 \\
- Porto Belo & 28,3 & 1,0 & 4,33 & 0,9 \\
- São Francisco do Sul & 36,9 & 1,3 & 4,24 & 0,9 \\
\hline Litoral Sul $\quad$ Garopaba & 46,1 & 1,7 & 7,56 & 1,6 \\
- $\quad$ Laguna & 74,3 & 2,7 & 8,17 & 1,7 \\
\hline
\end{tabular}

Fonte: Estudo da Demanda Turística/SANTUR - 2001 (In: LINS et al, 2002) 
Dessa maneira, a diversidade e a abrangência do potencial turístico em Santa Catarina impõem reconhecer a possibilidade, e mesmo a necessidade, no âmbito da promoção do desenvolvimento local e regional, de uma melhor utilização dos atributos existentes. Isso haveria de acontecer no marco de uma "interiorização" efetiva do "fato turístico" e, sem concessões, também no da preservação e valorização dos elementos que compõem os patrimônios socioambientais, paisagísticos e histórico-culturais.

Embora desde meados dos anos 80 a diferença entre os números de turistas nacionais e estrangeiros apresente um constante crescimento em benefício do fluxo brasileiro (Figura 1), a presença de argentinos é um traço saliente do turismo catarinense. Na alta estação de 2005, por exemplo, os turistas estrangeiros representaram, de acordo com estimativas da SANTUR, 7,2\% do total de visitantes no estado. Como a permanência média dos estrangeiros é maior do que a dos nacionais (em janeiro e fevereiro de 2005, 11,74 dias contra 8,72 dias), a movimentação dos primeiros representou na verdade pouco menos de 1/10 de todos os pernoites turísticos em Santa Catarina. Mas não é só em relação à permanência média que o contingente estrangeiro apresentou dados superiores. O gasto médio diário estimado para este fluxo foi de US\$ 23,81, quase 19\% maior do que o do fluxo nacional (que não superou US\$20,08).

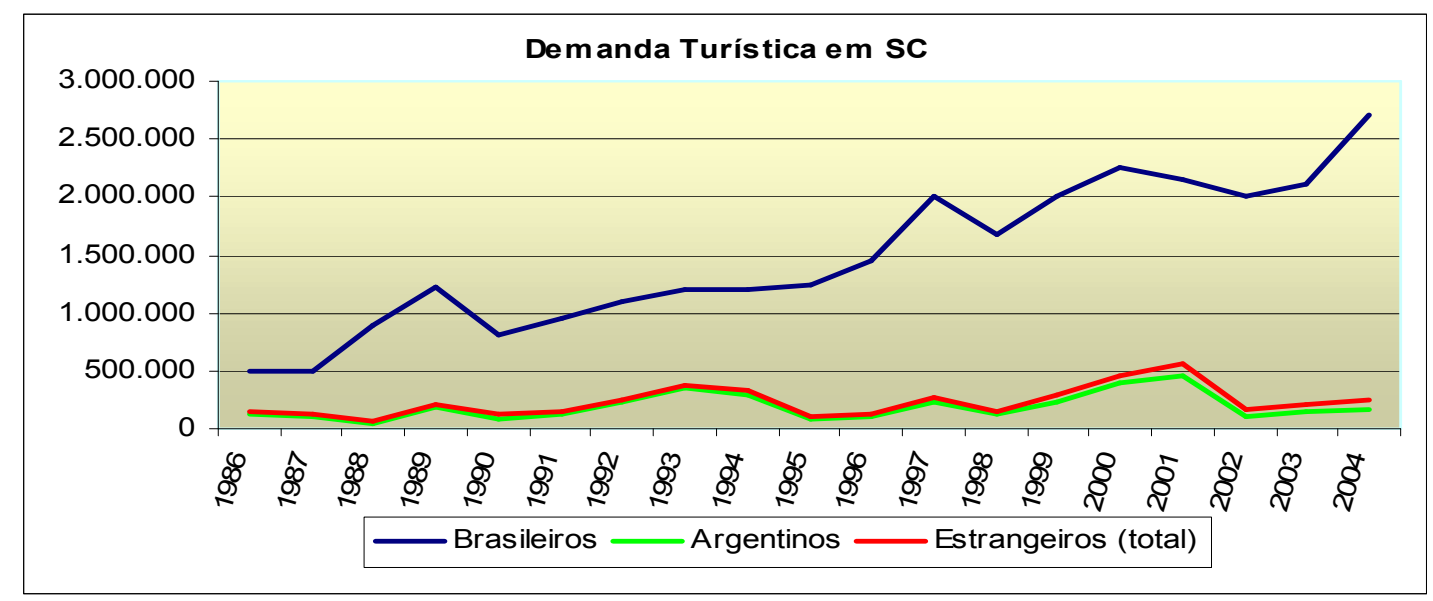

Figura 1: Evolução da demanda turística em Santa Catarina: 1986-2004 Fonte: SANTUR 
Ora, na esmagadora maioria dos casos, o fluxo internacional no estado possui origem argentina: em 2003, segundo dados da EMBRATUR, esta origem representou $69 \%$ daquele total (EMBRATUR, 2004); na alta estação de 2005, os cálculos da SANTUR indicam 74,1\%, uma origem estrangeira seguida de muito longe, em segundo lugar, pela paraguaia, com apenas $12,4 \%$ (SANTUR, 2005). A contribuição da Argentina para o turismo de origem externa em Santa Catarina é indicada na já referida figura 1, que cobre quase dois decênios de observação. As figuras 2 e 3, que têm a mesma amplitude temporal, apresentam respectivamente o comportamento da receita gerada pelos turistas, permitindo observar a participação de argentinos, e a sintonia, no que concerne a estes, entre número de turistas e volume de gastos.

Em que medida a presença de turistas argentinos em Santa Catarina tem sido afetada pelas condições econômicas do país vizinho? As relações cambiais entre Brasil e Argentina têm repercutido na movimentação turística e nos respectivos gastos em Santa Catarina? A próxima parte do artigo ocupa-se desse tipo de indagação.

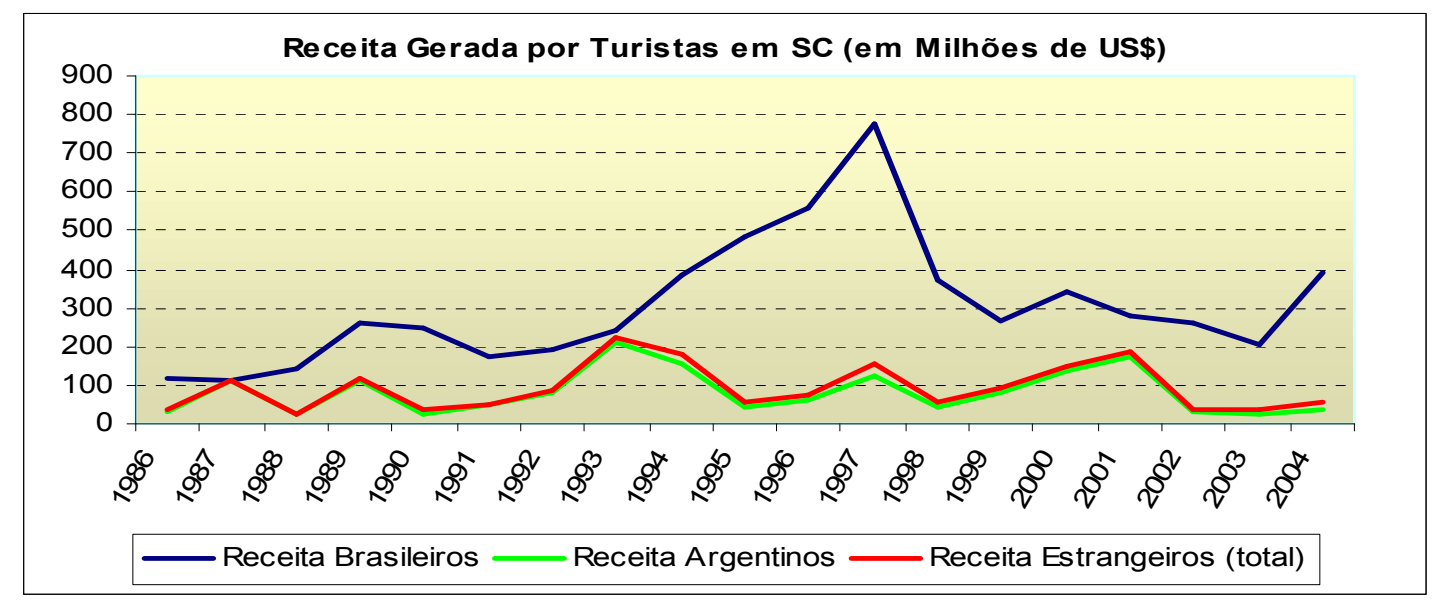

Figura 2: Receita turística em Santa Catarina: 1986-2004 (US\$ Milhões)

Fonte: SANTUR 


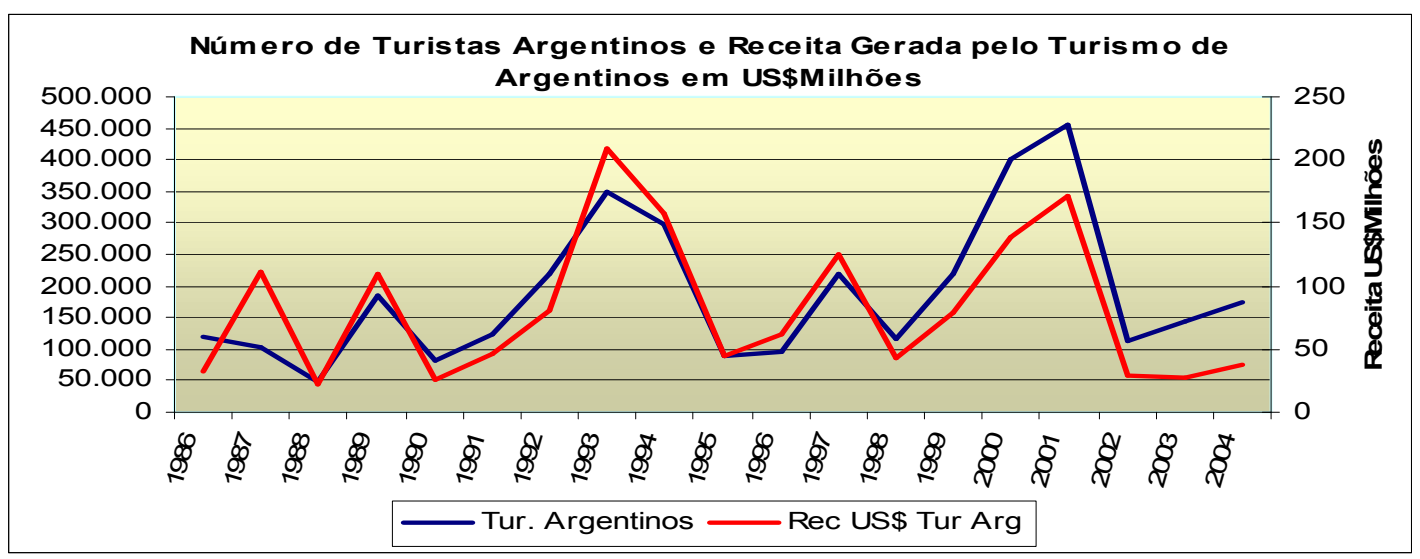

Figura 3: Turistas argentinos em Santa Catarina: quantidade e receita gerada em US\$ Milhões entre 1986 e 2004

Fonte: SANTUR

\section{Macroeconomia Argentina e Turismo Catarinense: explorando possíveis conexões}

A Argentina foi um dos países latino-americanos que seguiu mais à risca as recomendações de ajuste macroeconômico do chamado Consenso de Washington. Para os organismos internacionais que monitoram as reformas implementadas em escala nacional, o país vizinho cintilou entre os que, almejando maior eficiência no uso dos recursos e incremento na competitividade - com repercussões nos investimentos, nas exportações e no crescimento econômico de longo prazo -, estabilizaram os preços, liberalizaram o comércio externo, privatizaram e atraíram investimentos estrangeiros.

Peça chave desse turbilhão foi o Plano de Convertibilidade, conhecido como Plano Cavallo, de 1991. No âmbito desse plano, a Argentina passou a abrigar um regime cambial de currency board, introduzido por lei, quer dizer, um regime de câmbio fixo em relação ao dólar dos Estados Unidos. Isso significou moeda apreciada e inflação reduzida, traços que, associados às mudanças estruturais já indicadas, suscitaram uma grande reestruturação do aparelho produtivo daquele país (CHUDNOVSKY et al., 1996).

$\mathrm{Na}$ esteira das mudanças, e com o forte ingresso de capitais externos, o comportamento do PIB argentino só fez contraste com o observado na segunda metade dos anos 80. Até 1992-93, a taxa 
de crescimento adentrou trajetória de rápido crescimento, mantendo-se mais ou menos assim até meados dessa década. Como mostra Saludjian (2004), entretanto, a arrancada deu-se em contexto de forte volatilidade macroeconômica, querendo isso dizer uma expansão cercada por enorme instabilidade. Em 1995, as repercussões da grave crise mexicana - enfeixadas no chamado Efeito Tequila - atingiram em cheio a Argentina e tiveram grande impacto na sua taxa de crescimento.

Desvalorizar o câmbio naquele momento poderia ter sido uma resposta coerente à conjuntura adversa, mas o calendário eleitoral (Carlos Menem disputava a reeleição) inibiu qualquer ação que pudesse afetar a credibilidade do regime cambial, pedra angular do Plano de Convertibilidade e substrato do entusiasmo com a economia que caracterizara o período anterior. Além disso, o momento era de moeda valorizada também no Brasil, que desde a implementação do Plano Real, em 1994, fazia vigorar um regime de bandas cambiais. Isso possibilitava ao país vizinho desfrutar, no âmbito do esquema de integração referente ao Mercosul, do mercado brasileiro como destino privilegiado das suas exportações.

Entretanto, as condições internacionais se deterioraram ainda mais, tanto assim que o Brasil, de certa forma poupado do Efeito Tequila, viu-se obrigado a realizar uma forte desvalorização da sua moeda no início de 1999. Com efeito, premido por enormes dificuldades, e em meio à queda de braço interna nos campos da política e da economia, o Brasil sepultou o regime de bandas cambiais e passou a utilizar a taxa de câmbio flexível, um formato depois seguido, a partir de 2002, por um sistema de câmbio flutuante administrado pela autoridade monetária. Assim procedendo, no final dos anos 90, esse país evitou a explosão de uma crise nas proporções do que viria a ocorrer no país vizinho poucos anos depois, uma crise para a qual a própria mudança cambial brasileira não deixou de contribuir: as conseqüências da desvalorização brasileira para as exportações argentinas foram claras, e isso influenciou as decisões sobre investimentos (os fluxos de investimentos externos diretos na Argentina entraram em rota francamente descendente) e sobre a localização de unidades produtivas, em benefício do Brasil.

O corolário dessa progressão de dificuldades na Argentina foi o traumático abandono do Plano de Convertibilidade no final de 2001. Conforme descrito por Saludjian (op cit.), os depósitos bancários foram congelados, com proibição de saques acima de um certo limite por pessoa. Ao mesmo tempo, os depósitos foram classificados entre os que representavam contas correntes e de poupança em peso, e também aplicações fixas em peso ou em dólar, de um lado, e todos os 
demais depósitos, em pesos ou dólares, de outro lado. Os primeiros ganharam o apelido de corralito, e concentravam mais de $70 \%$ dos depósitos totais; os segundos foram chamados de corralón, e correspondiam aos tipos de depósitos mais utilizados pelas pessoas mais ricas. Inicialmente, essa conduta governamental draconiana não deveria se prolongar por mais de três meses, mas o período de vigência acabou se revelando de quase um ano e meio, permanecendo até meados de 2003. Dessa forma, não admira o clima de manifestações e de quase ruptura institucional que se instalou no país vizinho durante um bom tempo. A taxa de crescimento do PIB não deixou de acusar os graves problemas: em 2002, o encolhimento girou em torno de $10 \%$.

Para o que interessa neste artigo, o importante é frisar que, em todo o período coberto pelos dados macroeconômicos e de turismo aqui utilizados (de 1986 a 2004), o quadro argentino apresenta correlação negativa com o comportamento do número de turistas daquele país em Santa Catarina: o coeficiente de correlação encontrado entre a evolução da taxa de crescimento do PIB da Argentina e a evolução do contingente de turistas argentinos no estado é de -0,027 (Figura 4).

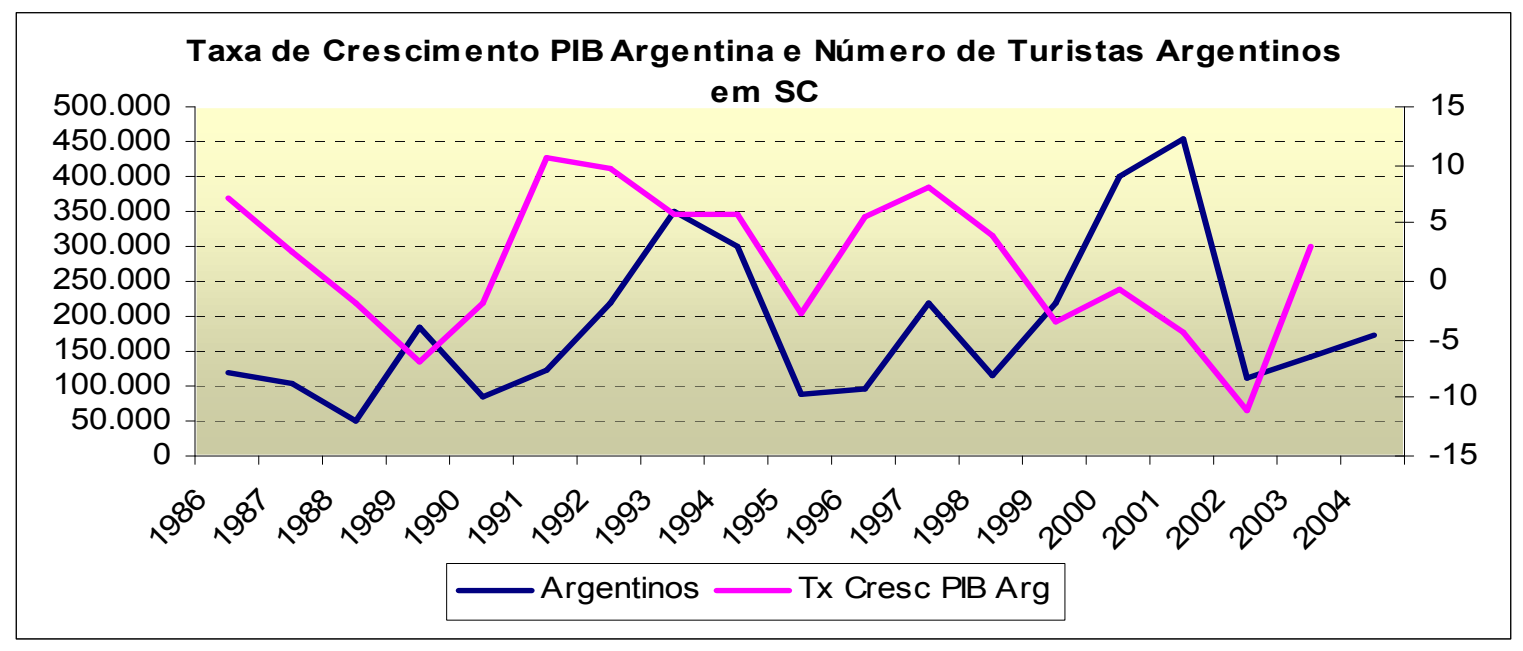

Figura 4: Taxa de crescimento do PIB argentino e turistas argentinos em Santa Catarina: 1986-2004

Fontes: Taxa de crescimento do PIB da Argentina: Séries Temporais do Banco Central do Brasil; número de turistas argentinos em Santa Catarina: SANTUR

Até 1990, a queda livre da taxa de crescimento do PIB foi ombreada por números de turistas primeiramente declinantes, depois em rápida ascensão. A posterior escalada das taxas do PIB foi acompanhada só com defasagem de um ou dois anos por comportamento no mesmo sentido dos 
números de turistas, o mesmo sendo observado na posterior seqüência de contração, nova recuperação e outro declínio, até quase o final da década. A partir de 1999, o contraste acentuouse mais uma vez: a taxa de crescimento do PIB mostra-se negativa, mas a movimentação de turistas dá um salto, triplicando em 2001. Daí em diante restabelece-se uma certa sintonia de movimentos. O recuo da taxa do PIB, até o dramático patamar de 2002, e a sua pálida recuperação em 2003 e 2004 assistem a um concomitante declínio e, depois, aumento - embora muito ligeiro - na quantidade de turistas. Claro que o mergulho da taxa e do número de turistas entre 2001 e 2002 é coerente com a extrema degradação do quadro socioeconômico amargada pela Argentina, como tangenciado anteriormente.

No atacado, portanto, o comportamento do PIB argentino não "explica" o fluxo de turistas para Santa Catarina. Entretanto, é possível considerar que, principalmente entre 1990 e 1998, houve movimentos de mesmo sentido entre as duas variáveis. O aspecto a ser realçado é que isso ocorreu com defasagem temporal. Ao que parece, a situação criada sobretudo pelas fases de recuperação (mas também de declínio) das taxas de crescimento produziu efeitos na movimentação turística somente algum tempo depois. Tal desdobramento não é desprovido de lógica: a alta volatilidade macroeconômica imporia um período de "decantação" das reorientações na trajetória da economia, gerando resultados com algum atraso no setor de viagens e turismo.

O comportamento do PIB tampouco "explica” o perfil da receita gerada pelos argentinos, já que o coeficiente de correlação entre a taxa de crescimento do produto argentino e os gastos efetuados pelos turistas desse país em Santa Catarina, entre 1986 e 2004, é de 0,050 (Figura 5). Isso não surpreende, em virtude da elevada - e evidente - correlação existente entre o número de turistas argentinos e a receita gerada por tais turistas (coeficiente de correlação igual a 0,843), como deixou claro a figura 3, já apresentada. Do mesmo modo como na anterior associação de variáveis, de 1990-91 a 1998-99 observa-se paralelismo com defasagem temporal, como se só algum tempo depois as direções tomadas na variação do PIB gerassem efeitos correspondentes no fluxo turístico e, por extensão, no volume de gastos realizados em Santa Catarina. 


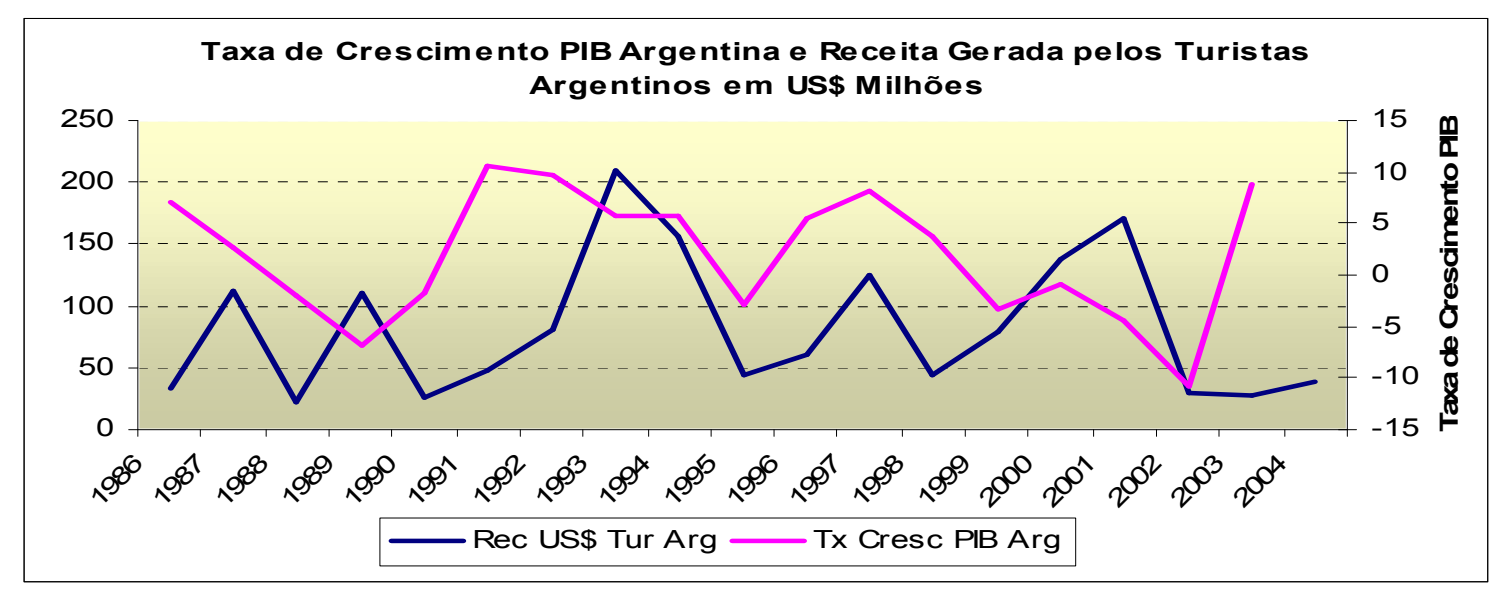

Figura 5: Taxa de crescimento do PIB da Argentina e receita gerada por turistas argentinos em Santa Catarina (em US\$ Milhões): 1986-2004

Fontes: Taxa de crescimento do PIB da Argentina: Séries Temporais do Banco Central do Brasil e /ou do Banco da Argentina, obtida pelo cálculo da variação percentual do PIB; Receita gerada pelos turistas argentinos em Santa Catarina: divisão da receita em R \$ pelo dólar médio (cf. divulgado pela SANTUR), com posterior multiplicação por 0,000001

Diferente foi a correlação encontrada entre o comportamento da taxa de câmbio da moeda brasileira frente à moeda argentina e o número de turistas argentinos em Santa Catarina. Aqui a associação é mais clara: o coeficiente calculado foi de 0,731 , sugerindo que a relação cambial “explica”, em algum grau, a demanda argentina (Figura 6). A razão é óbvia: taxa de câmbio elevada significa maior poder de compra do Peso no Brasil, e isso amplia a sedução dos atributos turísticos locais. Pode-se dizer, com efeito, que, nos períodos de alta taxa de câmbio, o baixo custo para visitantes estrangeiros dos serviços de hospedagem e alimentação, passando pelo entretenimento e o lazer em geral, torna quase irresistíveis as atrações catarinenses. Em decorrência, ficam ainda mais convidativos os deslocamentos de centenas de quilômetros que mesmo em outras conjunturas cambiais não inibem os que se aventuram nos vôos charter, multiplicados na alta estação, e na malha rodoviário do Cone Sul. 


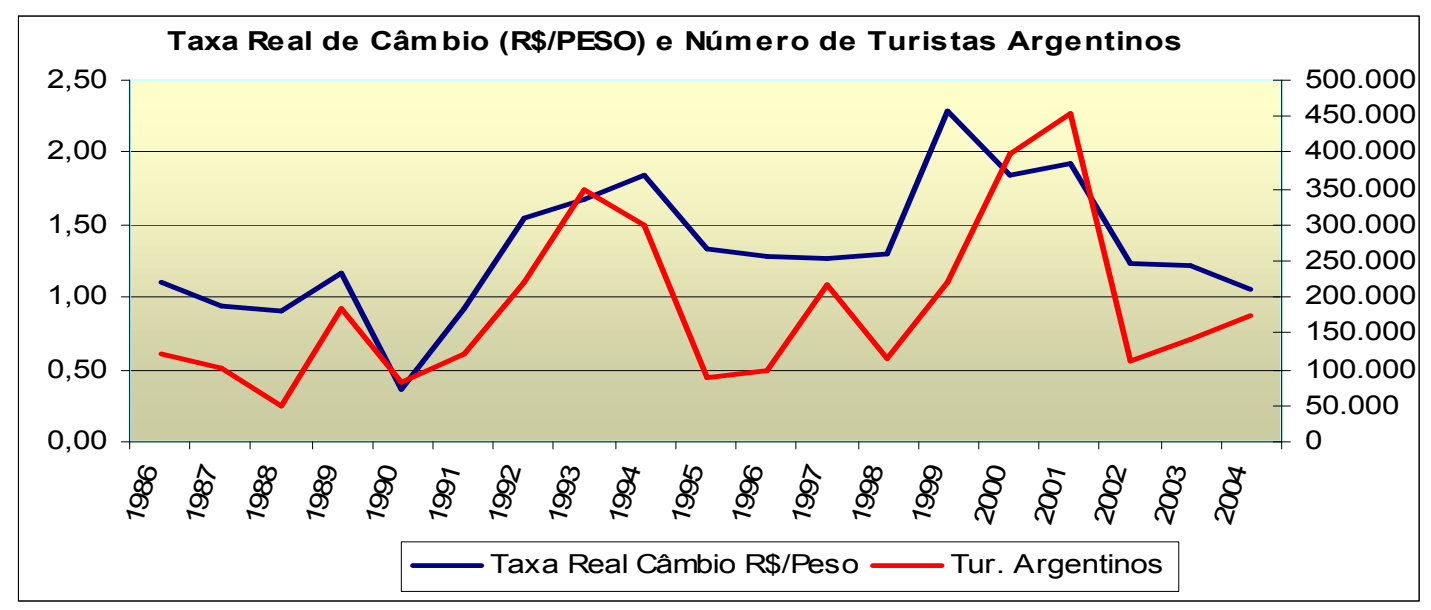

Figura 6: Taxa real de câmbio (R\$/Peso) e número de turistas argentinos em Santa Catarina: 1986-2004

Fontes: Taxa real de câmbio (R $\$ / P e s o)$ : taxa real de câmbio do Brasil / taxa real de câmbio da Argentina (a taxa real de câmbio da Argentina utilizada corresponde à média de janeiro e fevereiro; seu cálculo implicou a multiplicação da taxa nominal de câmbio da Argentina pelo resultado da divisão do índice CPI dos Estados Unidos pelo índice da Argentina; Número de turistas argentinos: obtido com a multiplicação do total de turistas estrangeiros pela percentagem de argentinos, conforme divulgado pelo SANTUR

Também merecedora de algum realce é a correlação detectada entre a taxa de câmbio envolvendo o Real e o Peso argentino, de um lado, e a receita gerada pelos turistas do país vizinho em território catarinense, de outro lado (Figura 7). Mesmo que a situação seja menos expressiva do que a anterior, ainda assim essas variáveis apresentam um coeficiente de correlação de 0,593985 no período observado. Vale assinalar que o desenho das respectivas curvas ganha maior discrepância mútua a partir do final dos anos 90 . Ora, sendo tal diferença mais acentuada, ao que parece, do que a observada na relação entre taxa de câmbio e número de turistas, objeto da figura precedente, cabe associar tal quadro com o nível de gastos médios dos visitantes. E de fato, um exame dos dados disponibilizados pela SANTUR (obtidos em www.sol.sc.gov.br/santur) revela que, por exemplo, entre 2001 e 2003, o gasto médio dos turistas estrangeiros em Florianópolis (contingente cuja grande maioria é formada por argentinos, como já se mostrou) caiu de US\$ 36,90 para US\$ 19,0, uma contração de nada menos que 48,5\%. Em 2004 e 2005, houve progressão para US\$ 23,6 e depois para US\$ 27,0, um patamar ainda muito distante do atingido em anos anteriores. 


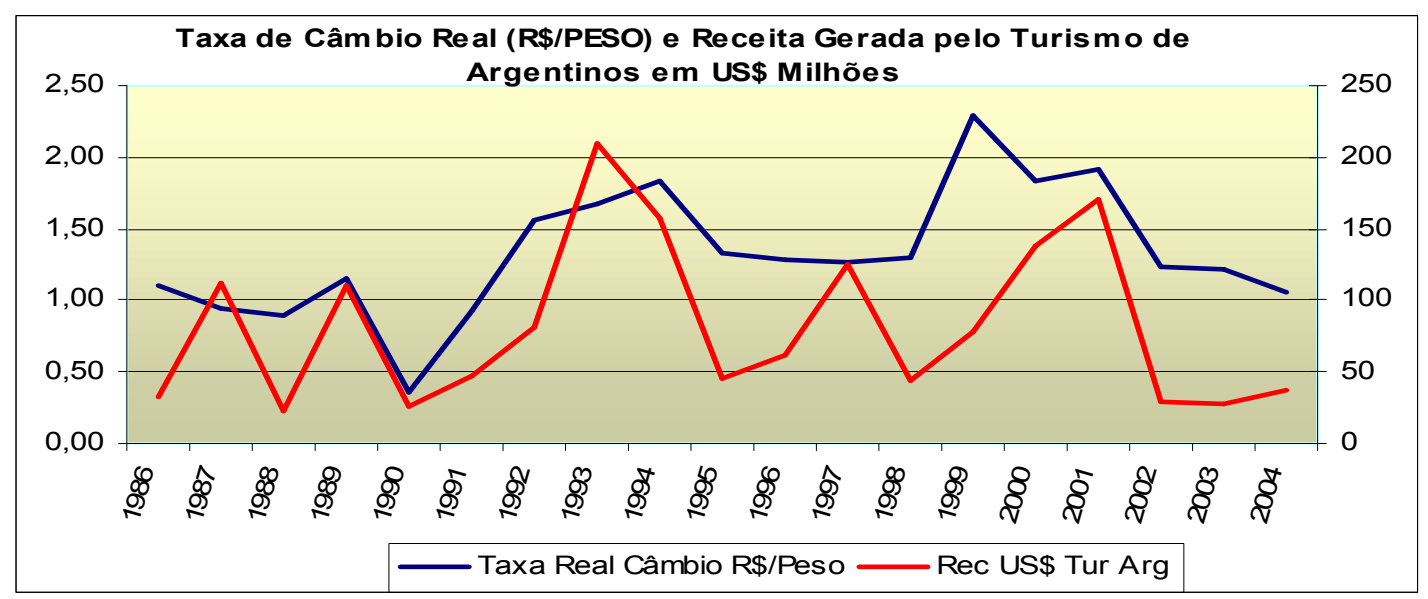

Figura 7: Taxa de câmbio real (R\$Peso) e receita (em US\$) gerada por turistas argentinos em Santa Catarina: 1986-2004

Fontes: Taxa real de câmbio (R $\$ / P e s o)$ : taxa real de câmbio do Brasil / taxa real de câmbio da Argentina (a taxa real de câmbio da Argentina utilizada corresponde à média de janeiro e fevereiro; seu cálculo implicou a multiplicação da taxa nominal de câmbio da Argentina pelo resultado da divisão do índice CPI dos Estados Unidos pelo índice da Argentina; Receita (em US\$ Milhões): obtida com a divisão da receita em Reais pelo dólar médio (divulgado pela SANTUR), com multiplicação por 0,000001

Antes da explosão da crise argentina, a diminuição da receita talvez reflita a vinda de turistas com menor poder aquisitivo, atraídos pelas vantagens outorgadas pela relação cambial. A opção de muitos turistas pelo aluguel de imóveis como meio de hospedagem, em detrimento dos hotéis - a título de ilustração pode-se assinalar que, entre 2000 e 2005, os pernoites turísticos (de nacionais e estrangeiros, somados) em casas e apartamentos de aluguel em Florianópolis variaram de $42,9 \%$ a $24,3 \%$ do total (cf. dados obtidos em www.sol.sc.gov.br/santur) - concorre para gastos menores, pois uma família inteira (quando não mais de uma) tende a se alojar num único apartamento ou casa, comprimindo o gasto médio em alojamento e alimentação. Com a deterioração das condições econômicas na Argentina, a queda da receita gerada por esses turistas em Santa Catarina parece coerente com a forte e generalizada contração das disponibilidades financeiras que os habitantes daquele país passaram a amargar em nível pessoal.

\section{Considerações finais}

O fluxo turístico argentino, representante de maior destaque entre os movimentos de estrangeiros que se dirigem a Santa Catarina em busca de lazer, na perspectiva de uma evasão do cotidiano, não é refratário às condições macroeconômicas. Isso parece menos verdadeiro em relação ao 
comportamento do PIB do país vizinho, embora considerações sobre defasagem temporal entre as idas e vindas da taxa de crescimento do produto e os reflexos na presença de turistas argentinos em solo catarinense possam ter lugar numa apreciação do problema, como se indicou. O terreno em que a influência da conjuntura macroeconômica se faz realmente sentir é, antes de tudo, o das relações cambiais. Com efeito, entre as variáveis de cuja inter-relação a presença de argentinos logra ser melhor "explicada", a taxa de câmbio Real/Peso foi a que mais se destacou na pesquisa que embasou este artigo. Note-se que os resultados encontrados são consistentes com os das estimações econométricas de Rabahy $(1990 ; 1992)$ envolvendo o número de turistas argentinos que ingressam no Brasil, embora seja necessário ressaltar que os períodos de tempo considerados na abordagem desse autor sejam diferentes do que é coberto neste artigo e que sua análise não se restringe, como ocorre aqui, a Santa Catarina.

Além de ser uma constatação importante em si mesma, esse resultado parece sugestivo sobre as possibilidades e limites das políticas locais de promoção do turismo. Se a macroeconomia é determinante, em grande medida, do fluxo turístico - no caso em foco, do fluxo originado na Argentina -, cabe indagar sobre os graus de liberdade de fato existentes para a formulação e implementação de medidas em nível de áreas turísticas, e sobre o alcance e a eficácia de tais medidas. Vale a pena, em conjunturas cambiais adversas à vinda de estrangeiros, concentrar os esforços na atração de tais fluxos? Ou o trade turístico, pilotado pelas instituições públicas e privadas que gravitam em torno do setor, deveria ser suficientemente ágil e flexível para explorar mercados que acenassem, a cada período, com resultados mais significativos?

Enfim, trata-se de interrogações, entre diversas outras, com as quais toda tentativa séria e conseqüente de planejar e conduzir o desenvolvimento do turismo em Santa Catarina necessita lidar. Das respostas escolhidas haverá de ser desenhado o futuro do setor de turismo nessa porção do Brasil meridional.

\section{Referências Bibliográfica}

CHUDNOVSKY, D. et al. 1996. Los límites de la apertura: liberalización, reestructuración productiva y medio ambiente. Buenos Aires: Alianza.

EMBRATUR. 2004. Anuário Estatístico da Embratur - 2004. Brasília: Ministério do Turismo/Instituto Brasileiro de Turismo.

FARAH, P. D. 2002. Turismo religioso explode em Nova Trento. Folha de S. Paulo, p. F14, 27 maio. 
FOLHA DE SÃO PAULO. 2001. SC investe para substituir turista argentino. Folha de S. Paulo, p. B1, 28 dez.

KRIPPENDORF, J. 1989. Sociologia do turismo. Rio de Janeiro: Civilização Brasileira.

LAGE, B. H. G.; MILONE, P. C. 1991. Economia do turismo. Campinas: Papirus.

LIM, C. 1997. Review of international tourism demand models. Annals of Tourism Research, v. 24, $\mathrm{n}^{\circ} 4$, p.835-849.

LINS, H. N. 1993. Herança açoriana e turismo na Ilha de Santa Catarina. Revista de Ciências Humanas, v. $10, n^{\circ} 14$, p. $89-117$.

LINS, H. N. et al. 2002. Turismo em Santa Catarina: caracterização e problemática. In: VIEIRA, P. F. (Org.). A pequena produção e o modelo catarinense de desenvolvimento. Florianópolis: APED Editora, $\mathrm{p}$. 209-261.

MADELEY, J. 1987. Turismo e Tercer Mundo. Desarrollo y Cooperación, nº 2, p. 4-5.

OURIQUES, H. R. 1998. Turismo em Florianópolis: uma crítica à industria pós-moderna. Florianópolis: Ed. da UFSC.

PAVEI, N. 2001. SC aposta no turismo de eventos. Diário Catarinense, p. 20, 16 dez.

PLIGER, M. 2002. Cetáceos roubam a cena no sul de SC. Folha de S. Paulo, p. F2, 21 out.

RABAHY, W. A. 1990. Fundamentos Econômicos e Quantitativos no Planejamento Turístico. Turismo em Análise, v. 1, $\mathrm{n}^{\mathrm{o}}$ 1, maio, p. 35-54.

. 1992. Modelo de predicción: un proyecto experimental en Brasil. Estudios y Perspectivas en Turismo, v. 1 , no 3, p. 198-215.

SALL, U. 1987. Cuando los turistas llegaron: a quién se sirve el turismo internacional en el Tercer Mundo. Desarrollo y Cooperación, ñ 2, p. 8-11.

SALUDJIAN, A. 2004. Trajetórias de crescimento e volatilidade macroeconômica no Mercosul: alguns elementos de análise empírica. Revista da Sociedade Brasileira de Economia Política, no 14, p. 48-70, jun.

SANTUR. 2005. Pesquisa Mercadológica - Estudo da Demanda Turística. Sinopse Comparativa 2003, 2004 e 2005. SANTUR/Gerência de Planejamento, abril. Disponível: www.sol.sc.gov.br/santur Acesso em out. 2005.

SANTUR. S/D. Roteiros. Disponível em: www.sol.sc.gov.br/santur/Roteiros. Acesso em out 2005.

SESSA, A. 1983. Turismo e política de desenvolvimento. Porto Alegre: Uniontur.

VANIN, A. 2001. "Estado capta mais eventos neste ano". Gazeta Mercantil Santa Catarina, p. 1 e 3, 26 jul.

THE ECONOMIST. 2000. Wish your dollars were here. The Economist, Dec. $16^{\text {th }}$, p. 66 .

WORLD TRAVEL \& TOURISM COUNCIL (WTTC). 2005a. Executive Summary. The 2005 Travel \& Tourism Economic Research. London: WTTC. Disponível: www.wttc.org . Acesso em out. 2005.

. 2005b. Brazil. The 2005 Travel \& Tourism Economic Research. London: WTTC.

Disponível: www.wttc.org . Obtido: out. 2005.

\section{Recebido em: 29/11/2005 (1 ${ }^{\mathrm{a}}$ versão) $10 / 04 / 2006$ ( $2^{\mathrm{a}}$ versão) Aprovado em: 26/06/2006}

